\title{
Enhancement of DEN-induced liver tumourigenesis in hepatocyte-specific Lass2-knockout mice coincident with upregulation of the TGF-ß1-Smad4-PAI-1 axis
}

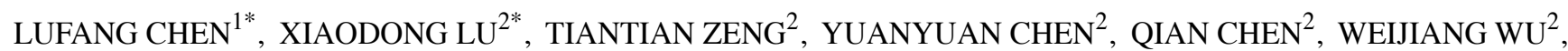 \\ XUN YAN $^{2}$, HONGHUA CAI ${ }^{2}$, ZHIJIAN ZHANG ${ }^{2}$, QIXIANG SHAO ${ }^{2}$ and WENXIN QIN ${ }^{1}$ \\ ${ }^{1}$ State Key Laboratory of Oncogenes and Related Genes, Shanghai Cancer Institute, Renji Hospital Shanghai Jiao Tong \\ University School of Medicine, Shanghai 200032; ${ }^{2}$ School of Medical Science and Laboratory Medicine, \\ Jiangsu University, Zhenjiang, Jiangsu 212013, P.R. China
}

Received September 17, 2013; Accepted November 12, 2013

DOI: 10.3892/or.2013.2908

\begin{abstract}
Longevity assurance homolog 2 of yeast LAG1 (Lass2) gene is capable of suppressing the proliferation and metastasis of several types of tumours including liver cancer. In the present study, hepatocyte-specific Lass2-knockout (Lass2 KO) and wild-type (WT) mice were exposed to the carcinogen, diethylnitrosamine (DEN), to induced liver tumours. At week 23 following DEN injection, tumours were produced in $100 \%$ of the Lass $2 \mathrm{KO}$ mice and $21.4 \%$ of the WT mice. At week 40, 100\% of the Lass $2 \mathrm{KO}$ mice and $78.6 \%$ of the WT mice developed tumours, with no distinct significant difference in tumour occurrences between the two genotypes; yet, tumours in the Lass $2 \mathrm{KO}$ mouse livers were more numerous and larger in size. Hepatocellular carcinoma (HCC) was confirmed by $\alpha$-fetoprotein (AFP). PCNA and EdU assays indicated more active proliferation whereas TUNEL assay revealed decreased apoptosis in Lass 2 KO livers, when compared with the WT control. The expression of plasminogen activator inhibitor type-1 (PAI-1), a tumour-promoting gene, in the liver tissues of the 2 genotypes was detected using qPCR and western blotting, showing that PAI- 1 levels were significantly elevated in Lass $2 \mathrm{KO}$ livers at week 40 following DEN introduction. Moreover, the expression of PAI-1-related
\end{abstract}

Correspondence to: Professor Xiaodong $\mathrm{Lu}$ or Professor Qixiang Shao, School of Medical Science and Laboratory Medicine, Jiangsu University, Zhenjiang, Jiangsu 212013, P.R. China

E-mail: lu_xdg@hotmail.com

E-mail:shao_qx@ujs.edu.cn

Professor Wenxin Qin, State Key Laboratory of Oncogenes and Related Genes, Shanghai Cancer Institute, Renji Hospital Shanghai Jiao Tong University School of Medicine, Shanghai 200032, P.R. China

E-mail:wqin@shsci.org

*Contributed equally

Key words: Lass2, knockout, DEN, carcinogenesis, PAI-1
TGF- $\beta 1$, Smad-4 and -7 was detected, displaying an elevation in TGF- $\beta 1$ and Smad-4 (not including Smad-7) in the Lass $2 \mathrm{KO}$ livers. Our data demonstrates that i) Lass 2 is a protective gene against DEN-induced liver tumourigenesis; and ii) upregulation of the TGF- $\beta 1-S m a d 4-P A I-1$ axis may contribute to the vulnerability of Lass2-knockout mice to DEN.

\section{Introduction}

Longevity assurance homolog 2 of yeast LAG1 (Lass2) gene, also known as ceramide synthase 2 , is a member of the CerS family and is responsible for the generation of long-chained ceramides $(1,2)$. Under a physiological condition, mRNA levels of Lass 2 are significantly higher than those of the other 5 CerSs, particularly abundant in the liver, kidney and brain in mice $(3,4)$. Since Lass 2 was firstly reported as a hepatocellular carcinoma (HCC)-suppressing gene $(5,6)$, a growing amount of research has provided experimental and clinical evidence of the close association between Lass 2 and some types of cancer, including prostate (7), breast (8) and bladder cancer (9). We hypothesized that Lass 2 may be a potential protective gene in the process of carcinogen-induced tumourigenesis. To test the hypothesis, we used a hepatocyte-specific Lass2knockout (Lass2 KO) transgenic mouse model for assessment of diethylnitrosamine (DEN)-induced liver tumourigenesis. The results demonstrated that at week 23 following DEN exposure, all female and male Lass $2 \mathrm{KO}$ mice developed liver tumours whereas in the wild-type (WT) group, only $28.6 \%$ of males and $14.3 \%$ of females developed tumours. At week 40 , although the majority of Lass $2 \mathrm{KO}$ and WT mice carried tumours and no significant difference in tumour occurrence was noted between the 2 genotypes, the tumours of livers from the Lass $2 \mathrm{KO}$ mice were more numerous and larger in size. The mRNA and protein levels of $\alpha$-fetoprotein (AFP), a widely used liver cancer marker, were markedly elevated in the liver (both in the tumour region and in the non-tumour region) of Lass $2 \mathrm{KO}$ mice. Our data indicate that the hepatocyte-specific deletion of Lass 2 in mice leads to a higher susceptibility to the carcinogen DEN. 
DEN, a chemical carcinogen, interacts with and damages DNA inducing mutations and initiating neoplastic alteration. The alterations in the genetic profile of liver tissues in Lass $2 \mathrm{KO}$ mice when compared with WT mice may be involved in the mechanism of the higher susceptibility to DEN. Plasminogen activator inhibitor type 1 (PAI-1) was found to be one of the markedly upregulated genes in the Lass $2 \mathrm{KO}$ liver tissues. In previous studies, $P A I-1$, the inhibitor of both tissue- and urokinase-type plasminogen activator (t-PA and u-PA, respectively), was suggested to be a tumour-promotor gene, which regulates cell proliferation, apoptosis, adhesion, migration, invasion and angiogenesis during the process of carcinogenesis $(10,11)$. The retarded growth of implanted tumours was observed in PAI-1knockout mice $(12,13)$. In the present study, we compared the mRNA and protein levels of PAI-1 in liver tissues (including the tumour region and the non-tumour region) following exposure to DEN in Lass $2 \mathrm{KO}$ and WT mice. We found that PAI-1 was markedly increased in the Lass $2 \mathrm{KO}$ liver tissues when compared with that in the WT specimens. We then examined the mRNA levels of TGF- $\beta 1$ and Smad-4 and -7 , which are closely related with $P A I-1(14,15)$. The data of the present study demonstrated that alteration of the TGF- $\beta 1-S m a d 4-P A I-1$ axis is involved in the mechanism of elevated susceptibility of Lass2 KO mice to DEN.

\section{Materials and methods}

Ethics statement. All protocols for animal care and use were approved by the Animal Care Committee of the Shanghai Cancer Institute and were in accordance with regulations for the Administration of Affairs Concerning Experimental Animals and National Institutes of Health Guidelines. All of the mice were housed in pathogen-free (SPF) animal facilities under a standard 12-h-light/12-h-dark cycle. Animals received free access to water and commercial mouse chow throughout the present study. Mice were sacrificed by cervical dislocation.

Transgenic mice. Hepatocyte-specific Lass $2 \mathrm{KO}$ mice were generated using the Cre/LoxP system for site-specific excisional DNA recombination. The background of the transgenic mice was $\mathrm{C} 57 \mathrm{BL} / 6 \mathrm{~J}$, and mice were obtained from the Jackson Laboratory (Bar Harbor, ME, USA). Mice carrying the floxed second exon of Lass2 (Lass2 LoxP $P^{+} /$LoxP $P^{-}$) were obtained from the Shanghai Research Centre for Model Organisms. Albumin-Cre transgenic mice expressing Cre recombinase under control of the hepatocyte-specific albumin promoter were purchased from the Jackson Laboratory. Lass 2 LoxP $P^{+} /$LoxP $P^{-}$were crossbred with Albumin-Cre transgenic mice to generate heterozygous transgenic mice, and the siblings were crossbred with each other to generate Lass $2 \operatorname{LoxP}^{+} / \operatorname{LoxP}^{+}$and $\mathrm{Alb}-\mathrm{Cr} \mathrm{e}^{+}$mice. The DNA of the mouse tail was extracted using the QIAamp DNA Blood kit (Qiagen Inc., Germany), and genotypes were identified by PCR assay. PCR was performed using the Takara Taq system (Takara Bio, Inc., Otsu, Japan) using sense, 5'-GGCTTC GTGTTGGTCTTCTGA-3' and antisense, 5'-ATTCCCTGGC ATCCACCTTTC-3' for Lass 2 LoxP primer pairs; and sense, 5'-GCGGTCTGGCAGTAAAAACTATC-3' and antisense, 5'-GTGAAACAGCATTGCTGTCACTT-3' for Cre primer pairs. Lass $2 \operatorname{LoxP}^{+} / \operatorname{LoxP}^{+}$and $\mathrm{Alb}-\mathrm{Cr}^{+}$mice were used as
Lass $2 \mathrm{KO}$ mice. Wild-type control was Lass 2 LoxP $P^{-} /$LoxP $P^{-}$and $\mathrm{Alb}-\mathrm{Cre}^{+}$mice. When mice were sacrificed after DEN treatment at week 23 or 40 , the genotypes of the brain, liver and kidney tissues were identified by PCR assay with the paired primers as sense, 5'-TATGTAGCCAGAGTCCAAGGC-3' and antisense, 5'-CACTATTGACCAGGCGAGGAG-3', western blotting and anti-Lass2 immunohistology (IHC) in order to confirm the hepatocyte-specific deletion of Lass2.

Hepatocarcinogen treatment. Groups of 14-day-old Lass $2 \mathrm{KO}$ and WT mice were administered a single intraperitoneal injection of the genotoxic hepatocarcinogen DEN (Sigma) dissolved in PBS at a dose of $20 \mathrm{mg} / \mathrm{kg}$ body weight or saline (no DEN). Mice were sacrificed respectively at week 23 and 40 following DEN or saline injections. The livers were weighed, the diameter of tumours $\geq 1 \mathrm{~mm}$ on the surface of the livers were enumerated and the sizes of tumours were measured. Part of the liver tissues was fixed in AAF $(100 \%$ alcohol $85 \mathrm{ml}$, acetic acid $5 \mathrm{ml}$, formalin $10 \mathrm{ml}$ ) for histological study, and the remaining part was frozen at $-80^{\circ} \mathrm{C}$ until use.

Histological study. The fixed liver, kidney and brain tissues were embedded in paraffin, sectioned into $4-\mu \mathrm{m}$ slices and anti-Lass2 immunohistochemical staining was performed to ascertain hepatocyte-specific deletion of Lass2. The liver sections were H\&E-stained for examination of morphological alteration after DEN treatment. Moreover, IHC staining of proliferating cell nuclear antigen (PCNA) and 5-ethynyl-2'-deoxyuridine (EdU) staining were performed for examining the proliferation, whereas terminal deoxynucleotidyl-transferasemediated dUTP-biotin nick end-labeling (TUNEL) assay was carried out for assessment of apoptosis in the DEN-treated livers.

Immunohistochemistry. For IHC staining, the standard protocol was performed. Briefly, sections were incubated with $3 \% \mathrm{H}_{2} \mathrm{O}_{2}$ to eliminate the endogenous peroxidase activity, then blocked with $5 \%$ bovine serum albumin (BSA), and then incubated with rabbit anti-Lass2 polyclonal antibody (1:100) (Beijing Biosynthesis Biotechnology Co., Ltd., Beijing, China) or rabbit anti-PCNA polyclonal antibody (1:100) (ProSci, Inc., Poway, CA, USA) at $4^{\circ} \mathrm{C}$ overnight, respectively. The sections were washed 3 times with PBS for 5 min each. For the Lass 2 assay, the sections were incubated with Alexa Fluor ${ }^{\circledR}$ 488-conjugated goat anti-rabbit antibody (1:100) (Invitrogen Life Technologies, Carlsbad, CA, USA). Images were captured using a Leica DM LB2 epifluorescence microscope. However, for PCNA detection, the sections were incubated with HRP-conjugated mouse anti-rabbit IgG (1:100) (ProSci, Inc.) for $1 \mathrm{~h}$ at $37^{\circ} \mathrm{C}$. Color was developed with DAB (KeyGen Biotech, Nanjing, China), and microscopic examination was performed with a bright field microscope (Motic BA210; Xiamen, China).

EdU assay. EdU assay was performed on mouse liver section using the EdU DNA Imaging kit (RiboBio, Guangzhou, China) according to the manufacturer's instructions. Briefly, $5 \mathrm{mg} / \mathrm{kg}$ EdU was intraperitoneally injected into mice $8 \mathrm{~h}$ before sacrifice. The mice were sacrificed under ether anaesthesia, and the liver sections were developed as indicated above. The slices 
were washed in a shaker with glycine $(2 \mathrm{mg} / \mathrm{ml})$ for $10 \mathrm{~min}$ and then incubated with $0.5 \%$ Triton X-100 for 10 min. Following washing with PBS for 2 times, the sections were incubated with Apollo reaction buffer for 10-30 min. Finally, after being washed with $0.5 \%$ Triton $\mathrm{X}-100$ for 3 times, methanol twice and PBS for 1 time in due order, the slices were stained with $100 \mu 1$ Hoechst 33342 (x1) for $30 \mathrm{~min}$ at room temperature (RT). Images were obtained using a Leica DM LB2 epifluorescence microscope. The EdU labeling index of the liver tissues was calculated as a percentage of EdU-positive cells to the total of Hoechst 33342-stained cells in each field, counted in 5 random x100 fields in 5 representative livers from each group.

TUNEL assay. Cell apoptosis in liver tissues was determined using a TUNEL kit (Beyotime Institute of Biotechnology, Jiangsu, China) according to the manufacturer's recommendations. Briefly, paraffin-embedded tissue sections were deparaffinized and rehydrated as above. The slides were treated with protease $\mathrm{K}(1: 500,20 \mu \mathrm{g} / \mathrm{ml})$ for $15 \mathrm{~min}$ at $37^{\circ} \mathrm{C}$, washed 3 times with PBS, incubated in TUNEL reaction buffer (Tdt enzyme $2 \mu \mathrm{l}$, fluorescent buffer $48 \mu \mathrm{l}$ ) for $60 \mathrm{~min}$ at $37^{\circ} \mathrm{C}$ while protecting from light, and again washed 3 times with PBS, then stained with $100 \mu 1$ Hoechst 33342 (x1) for 30 min at room temperature, and washed with PBS twice. Slides were observed under a Leica DM LB2 epifluorescence microscope. The apoptotic cell index was expressed as the average of five random areas of a single x100 field in a specific individual liver tissue, with 5 mice/group and 1 section/mouse.

Western blotting. Tissues were lysed in RIPA lysis buffer containing the protease inhibitor phenylmethanesulfonyl fluoride (both from Beyotime Institute of Biotechnology). The cell extracts were centrifuged at $12,000 \mathrm{x}$ g for $20 \mathrm{~min}$ at $4^{\circ} \mathrm{C}$, and the supernatants were used for experiments. The protein concentrations were determined with the BCA assay kit (Beyotime Institute of Biotechnology). The equivalent tissue proteins $(10 \mu \mathrm{g} /$ lane $)$ were subjected to electrophoresis and transferred onto PVDF membranes (Millipore, Bedford, MA, USA) via a semi-dry transfer system (Bio-Rad, Hercules, CA, USA). The membranes were blocked with $5 \%$ non-fat milk for $1 \mathrm{~h}$ at room temperature in TBST (50 mM pH 7.5 Tris, $0.9 \%$ $\mathrm{NaCl}$ and $0.1 \%$ Tween-20) and then incubated with a 1:200 dilution of the primary antibodies (anti-PAI-1, anti-AFP and anti-Smad-4 were purchased from Bioworld Technology, Inc.; anti-Lass2 was from Beijing Biosynthesis Biotechnology Co., Ltd; and anti- $\beta$-actin from Santa Cruz Biotechnology, Inc.) overnight at $4^{\circ} \mathrm{C}$. The membrane was washed then incubated with secondary antibody for $1 \mathrm{~h}$ at room temperature and developed using BeyoECL Plus kit (Beyotime Institute of Biotechnology) for $1 \mathrm{~min}$, then scanned by ChampChemi ${ }^{\mathrm{TM}}$ professional (Beijing Sage Creation Science Co., Ltd., Beijing, China).

RNA isolation and quantitative PCR ( $q P C R)$ analysis. Total RNA from different liver tissues including the non-DENtreated, DEN-treated non-tumour region and tumour region from the male Lass $2 \mathrm{KO}$ and WT mice (3 mice/group) at week 40 were, respectively, extracted using TRIzol (Invitrogen Life Technologies) and subjected to reverse-transcription using the miScript Reverse Transcription kit (Takara Bio, Inc.) to synthe-
Table I. Primers for QT-PCR.

\begin{tabular}{ll}
\hline Gene symbol & \multicolumn{1}{c}{ Primer } \\
\hline AFP & 5'-TGCGCTCTCTACCAGACCTT-3' \\
& 5'-ACAGGGCTTGCTTCATTCC-3' \\
PAI-1 & 5'-GCAACGGATAGACAGATCAAA-3' \\
& 5'-AGTCACCTACACTCTGAAATAAC-3' \\
Smad7 & 5'-TCTTCAACAGCCGGTAGTC-3' \\
& 5'-GGAAAGGTTAGCAGCAAGT-3' \\
Smad4 & 5'-CTTACCCACTGAAGGACATT-3' \\
& 5'-GTGGCGTTAGACTCTGC-3' \\
TGF- 31 & 5'-GTGGAAATCAACGGGATCAG-3' \\
& 5'-TTCTCTGTGGAGCTGAAGCA-3' \\
GAPDH & 5'-GCAAGGTCATCCCAGAG-3' \\
& 5'-AAGTCGCAGGAGACAAC-3'
\end{tabular}

$\alpha$-fetoprotein; PAI-1, plasminogen activator inhibitor type-1.

size cDNA, and comparative quantitative PCR (QT-PCR) was preformed using SYBR-Green (Takara Bio, Inc.) chemistry analysis in quadruplicates. Relative expression was calculated using the comparative threshold cycle $(\mathrm{Ct})$ method. The primers for AFP, PAI-1, TGF- $\beta 1$, Smad-4, Smad-7, GAPDH are shown in Table I.

Statistical analysis. All data are presented as means \pm standard error of the mean (SEM). Unpaired Student's t-test was used for statistical analysis. $\mathrm{P} \leq 0.05$ was considered to indicate a statistically significant result. All QT-PCR and western blot analyses were repeated at least 3 times. All statistical analyses were conducted using the GraphPad Prism 5.

\section{Results}

Establishment of hepatocyte-specific Lass2-knockout transgenic mice. Hepatocyte-specific Lass $2 \mathrm{KO}$ mice were produced using the Cre-LoxP system. Lass2-ABRLFn-pBR322 vector carrying 2 LoxP cassettes was inserted into the intron 1-2 and intron 2-3, respectively. The excision of Lass 2 was the result of the recombination event by one Cre recombinase enzyme controlled by the upstream Alb-promoter on the Lass2-ABRLFn-pBR322 which was able to identify the sequence between 2 LoxP cassettes (Fig. 1A). Mice carrying a floxed Lass 2 allele were mated with Alb-Cre transgenic mice that express the Cre recombinase in hepatocytes. The siblings that carried both floxed Lass 2 allele and Alb-Cre were selected by the genotyping of tail DNA and were named as Lass $2 \mathrm{KO}$ mice (Fig. 1B, lane 2). To confer hepatocyte-specific Lass 2 deletion, PCR assay and anti-Lass2 immunohistology of the liver, kidney and brain tissues were carried out. In Lass $2 \mathrm{KO}$ mice, liver tissue displayed the Lass2-knockout band whereas kidney and brain tissues did not (Fig. 1C). The phenotype was verified by western blotting, and the results showed the absence of the Lass2 protein from the liver tissues of Lass2 $\mathrm{KO}$ mice when compared with the control mice; no significant 
A

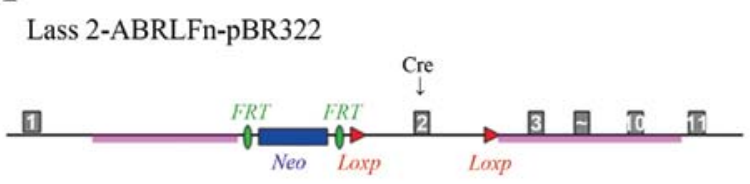

B

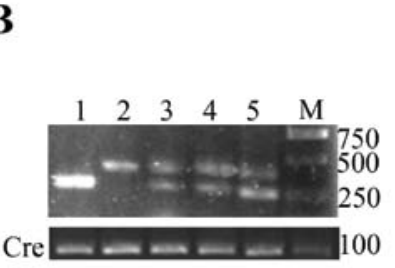

D

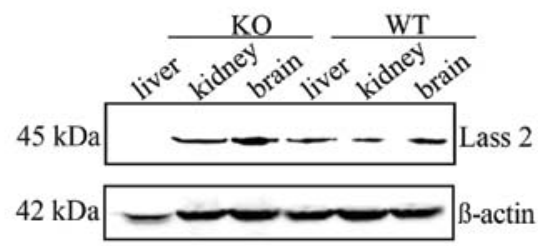

$\mathbf{E}$

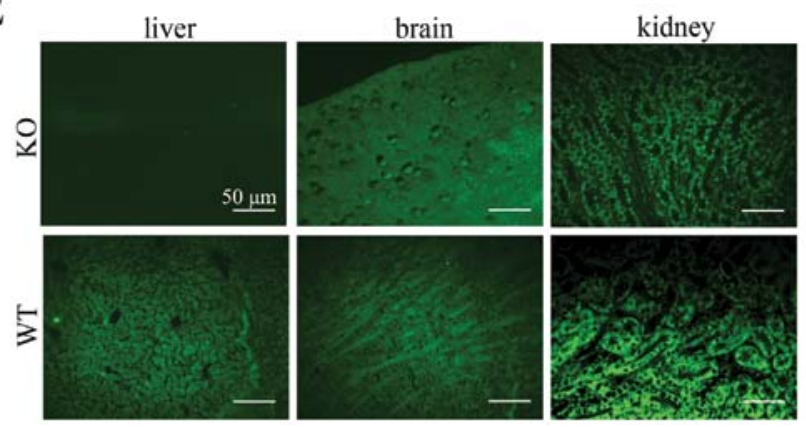

Figure 1. Establishment of liver-specific Lass 2 knockout mice. (A) Cre/LoxP system for site-specific excision of Lass2. Lass2-ABRLFn-pBR322 vector carrying 2 LoxP cassettes was inserted into intron 1-2 and intron 2-3, respectively; NeO cassette was inserted into intron 1-2. Expression of the NeO cassette in the cells enabled selection of positive stable clones with G418. Flip recombinase target site (FRT) on 2 sides of Neo cassette leading to excision of neo gene. The excision of Lass 2 was the result of the recombination even by one Cre recombinase enzyme on the Lass2-ABRLFn-pBR322 which identifies the sequence between 2 LoxP cassettes. (B) PCR analysis of genomic DNA of mouse tail. Lane 1 is the wild-type control. Lane 2 is the mouse carrying Lass 2 LoxP $P^{+} / L_{o x P} P^{+}$and Alb-Cre ${ }^{+}$which resulted and was named Lass $2 \mathrm{KO}$. Lane 3-6 is the mouse carrying Lass2 LoxP $P^{+} /$LoxP $P^{-}$and Alb-Cre ${ }^{+}$. (C) PCR analysis of genomic DNA of brain, kidney and liver tissue from Lass $2 \mathrm{KO}$ and WT mice. (D) Western blotting showed that the level of Lass2 was strongly decreased in the liver from Lass $2 \mathrm{KO}$ mice when compared with that in the livers of the WT rats, whereas no significant difference was noted in the brain or kidney tissues from the Lass $2 \mathrm{KO}$ mice or WT mice. (E) In the Lass $2 \mathrm{KO}$ mice, anti-Lass2 immunohistology of the liver demonstrated that the fluorescence signal for Lass 2 was not detected in the liver tissue, whereas Lass2-positive fluorescence signals were observed in the liver, kidney and brain tissues from the WT mice. Lass $2 \mathrm{KO}$, Lass 2 knockout; WT, wild-type.

difference in brain and kidney tissues was noted between the 2 groups (Fig. 1D). Immunohistology demonstrated that Lass2 signals were undetectable in the livers from Lass2 $\mathrm{KO}$ mice whereas they were visible in kidney and brain tissues (Fig. 1E).

Enhancement of DEN-induced liver carcinogenesis following hepatocyte-specific deletion of Lass2. The liver carcino-
Table I. Comparison of DEN-induced liver carcinogenesis between Lass2 KO and WT mice.

\begin{tabular}{lcclll}
\hline & \multicolumn{2}{c}{23 weeks } & & \multicolumn{2}{c}{40 weeks } \\
\cline { 2 - 3 } \cline { 6 - 6 } Genotype & $\begin{array}{c}\text { Male } \\
\text { ratio (\%) }\end{array}$ & $\begin{array}{c}\text { Female } \\
\text { ratio (\%) }\end{array}$ & & $\begin{array}{c}\text { Male } \\
\text { ratio (\%) }\end{array}$ & $\begin{array}{c}\text { Female } \\
\text { ratio (\%) }\end{array}$ \\
\hline $\begin{array}{l}\text { DEN-treated } \\
\text { Lass2 KO }\end{array}$ & & & & & \\
WT & $2 / 7(100)$ & $7 / 7(100)$ & & $7 / 7(100)$ & $7 / 7(100)$ \\
Saline-treated & & & & & \\
Lass2 KO & $0 / 7(0.0)$ & $0 / 7(0.0)$ & & $0 / 7(0.0)$ & $0 / 7(0.0)$ \\
WT & $0 / 7(0.0)$ & $0 / 7(0.0)$ & & $0 / 7(0.0)$ & $0 / 7(0.0)$ \\
\hline
\end{tabular}

DEN, diethylnitrosamine; Lass2 KO, Lass2 knockout; WT, wild-type.

genesis of mice was induced using the classical carcinogen DEN. In the well-established model of DEN-induced liver carcinogenesis, the development of tumour is usually monitored approximately 38-40 weeks following the treatment of DEN. We hypothesized that the loss of Lass 2 may accelerate the formation of tumours. Therefore, the mice were sacrificed at two time points: week 23 and 40, respectively, after DEN or saline treatment. Following DEN injection, at week 23 , notably, all the KO mice, either male or female, developed tumours in the livers, whereas only 2 out of 7 males and 1 out of 7 females in the WT group developed tumours. The difference in the tumour occurrence between the Lass $2 \mathrm{KO}$ and WT group was highly statistically significant $(\mathrm{P}<0.001)$. At week 40 following DEN treatment, although almost all mice from both groups developed tumours and no significant difference in tumour occurrence was noted between the 2 groups (Table II), in Lass2 KO group, the indices of liver weight/body weight, the numbers of tumours on the surface of livers and the average sizes of tumours were higher than these values in the control group (Fig. 2A and B). We also found a greater elevation in the AFP level in the Lass $2 \mathrm{KO}$ group (both in the tumour and non-tumour regions) when compared with its counterpart at week 40 (Fig. 2C). Histologic analysis of H\&E-stained liver sections from Lass $2 \mathrm{KO}$ and WT mice revealed that the tumours were hepatocellular adenomas/carcinomas, showing basophilic foci characterized by clearly defined margins, compression of the surrounding parenchyma, thicker trabeculae extensive fatty degeneration and Mallory bodies inside of the tumours (Fig. 2D). Unequivocal evidence of metastases or vascular invasion was not found. The results indicated that the deletion of Lass 2 resulted in the earlier occurrence of DEN-induced liver carcinogenesis and accelerated tumour growth.

Promotion of proliferation and inhibition of apoptosis in liver tumours following hepatocyte-specific deletion of Lass2. In our previous study, we found that overexpression of Lass 2 in a human liver cancer cell line inhibited proliferation of the cells in vitro (6). In the present study, we also found that the average size of tumours in the Lass2 KO group was larger than that of the control group. Therefore, we detected the 
A
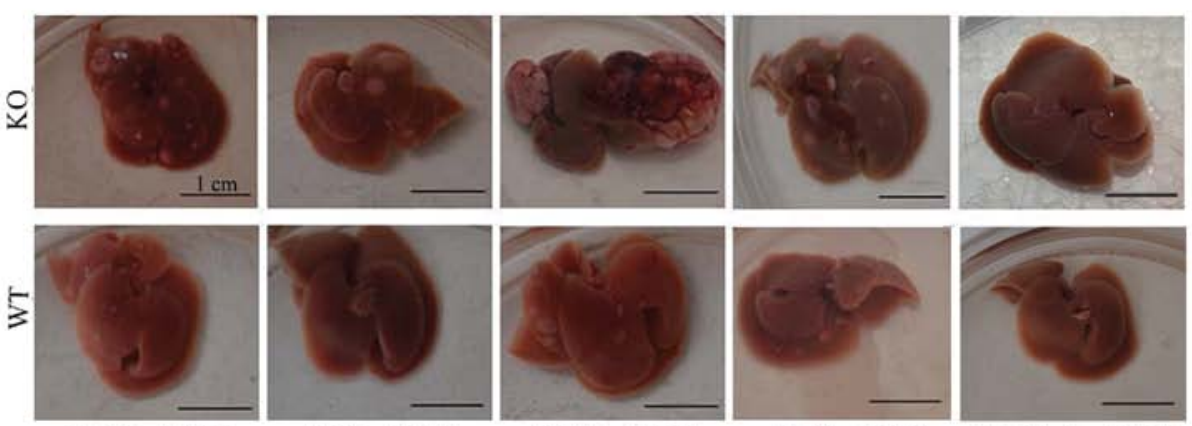

B

$\mathrm{M}, 23 \mathrm{w} / \mathrm{DEN}$

F, 23 w/DEN

$\mathrm{M}, 40 \mathrm{w} / \mathrm{DEN}$

F,40 w/DEN

M,40 w/no DEN
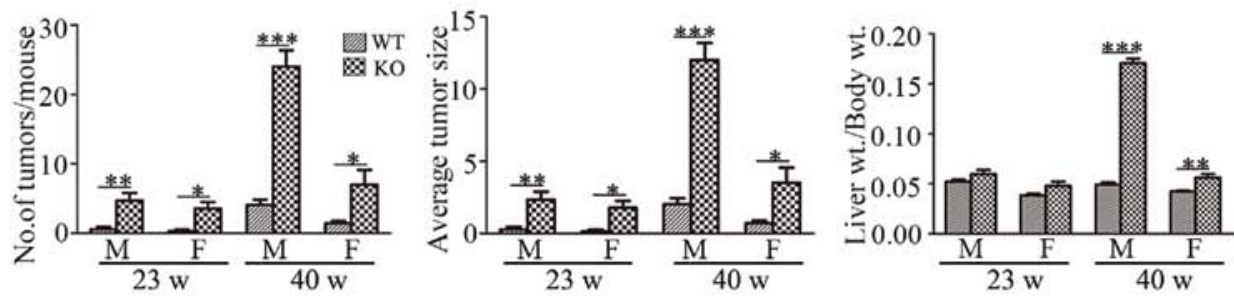

\section{40 weeks}
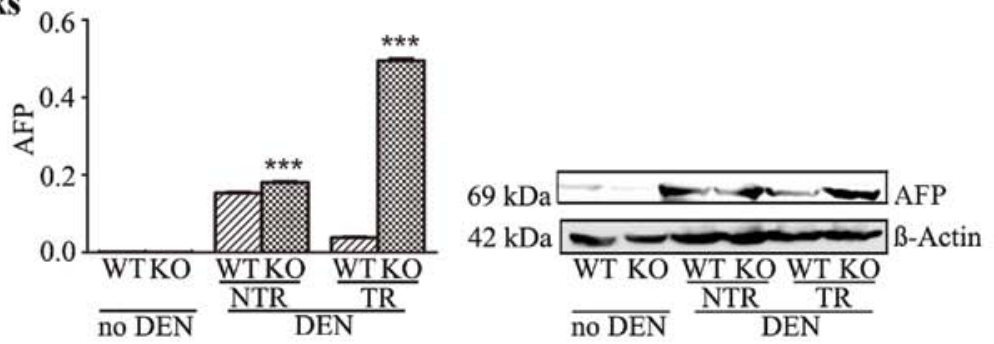

D
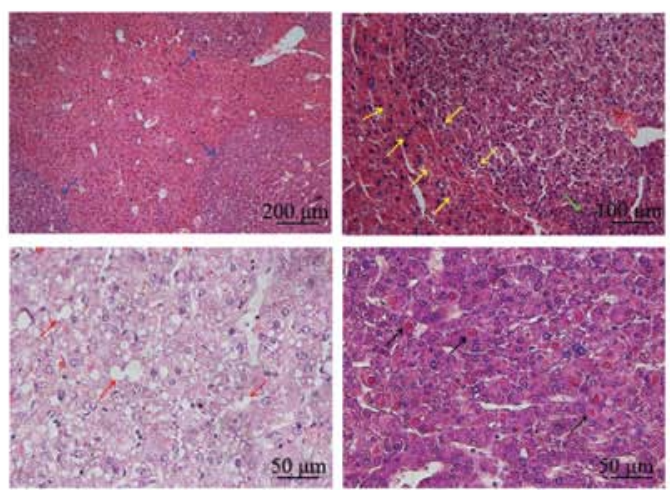

Figure 2. Hepatocyte-specific deletion of Lass2 enhances DEN-induced liver carcinogenesis. (A) Images are representative of livers carrying tumours, demonstrating the visible nodules on the surface of livers from male and female Lass $2 \mathrm{KO}$ and WT mouse at week 23 and 40 following DEN-treatment, respectively. At week 23, the livers from the Lass2 KO mice carried more small-sized nodules and at week 40 large-sized well-vascularized tumour nodules appeared with the dark-coloured non-tumour liver tissue in the Lass2 KO mice, whereas the WT and KO livers were visibly normal without DEN-treatment. (B) The ratios of liver to body weight, numbers of tumours and the average sizes of tumour nodules following DEN-treatment are summarized. These indices in the Lass $2 \mathrm{KO}$ mice were strikingly higher than those of the WT mice. The increased indices at week 40 when compared to week 23 implied the ongoing process of development of liver tumours. Moreover, the male mouse indices were higher than those of the female mice, indicating the higher susceptibility to DEN in males. (C) The expression of AFP in Lass2 KO livers was measured using QT-PCR analysis and western blotting. The level of AFP was barely detected in the two groups without DEN-treatment. After DEN injection, the level of AFP was significantly increased in the Lass2 KO livers, particularly in the tumour region. The western blotting shows the same trend as the results of QT-PCR analysis. (D) The examination of H\&E-stained paraffin-embedded sections of liver tissue demonstrated basophilic foci characterized by clearly defined margins (blue arrows), compression of the surrounding parenchyma (yellow arrows), thicker trabeculae (green arrows), extensive fatty degeneration (red arrows) and Mallory bodies (black arrows) inside the tumours. DEN, diethylnitrosamine; Lass2 KO, Lass2 knockout; WT, wild-type.

cell proliferation of liver tissues in male mice at week 23 with EdU assay (Fig. 3A), the expression of cell proliferation marker PCNA with IHC staining (Fig. 3B), and apoptosis with TUNEL assay (Fig. 3C). Quantification revealed an $\sim 8$-fold 
A
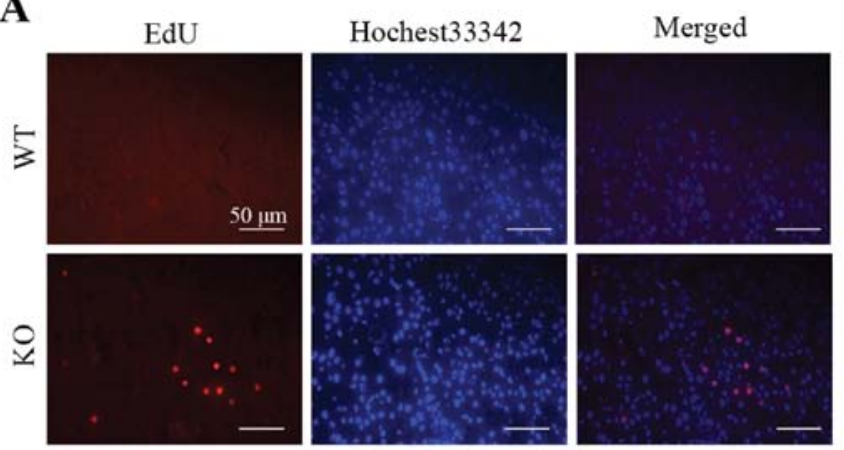

B

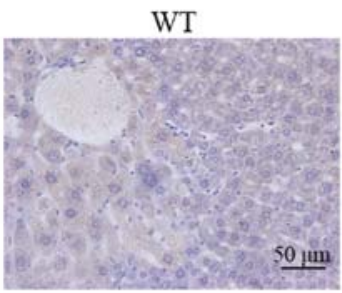

C
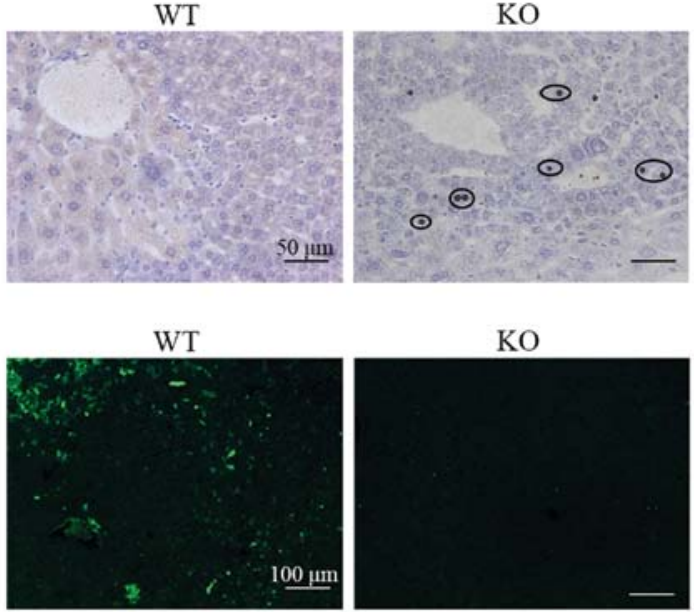

KO

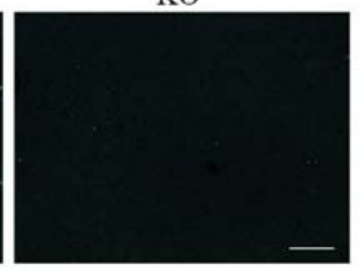

D
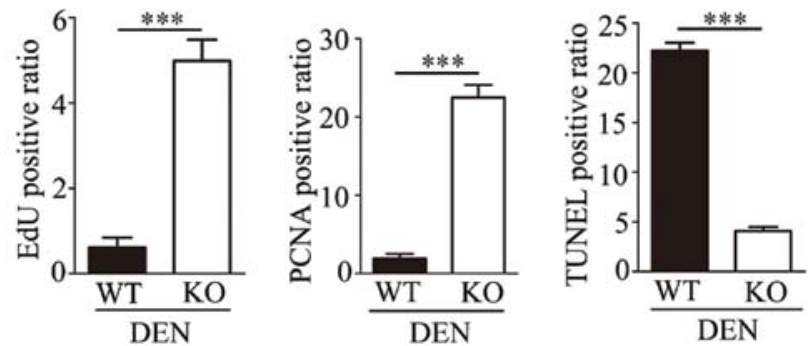

Figure 3. Lass2 KO livers after DEN-treatment exhibit increased proliferation and inhibition of apoptosis. The proliferation and apoptosis of liver tissue at week 23 after DEN treatment were detected with ethidium deoxyuridine (EdU) cell proliferation assay, anti-PCNA immunochemistry and TUNEL staining. (A) EdU cell proliferation staining of liver tissue from Lass $2 \mathrm{KO}$ and WT mice. Left, EdU-positive nuclei (red); middle, Hochest 33342-labeled nuclei (blue); right, overlay EdU- and Hochest 33342-labeled nuclei. The number of EdU-positive cells relative to the total number of cells was counted in each of 5 random x 100 fields of each section (5 mice/group, 1 section/ mouse). The histogram of the EdU-positive ratio (the number of EdUpositive nuclei/the number of total nuclei/field) is shown in $\mathrm{D}$, indicating that the DEN-treated Lass2 $\mathrm{KO}$ mice underwent more active proliferation in liver tissue than the control. (B) Anti-PCNA immunochemistry of liver tissues from Lass $2 \mathrm{KO}$ and WT mice shows PCNA-positive cells, indicated by circles. The histogram in D shows the average PCNA-positive ratio (PCNA-positive cells/total cells, counted in 5 random x100 fields, 5 mice/ group, 1 section/mouse). The number of PCNA-positive cells was higher in DEN-treated Lass2 KO liver when compared with the WT control, which is coincident with the previous result shown in A. (C) TUNEL staining of the liver tissues from Lass $2 \mathrm{KO}$ and WT mice (green). The histogram of average TUNEL-positive ratio (TUNEL-positive cells/total cells, in 5 random x100 field fields, 5 mice/group, 1 section/mouse) in D indicates that the number of TUNEL-positive cells was significantly less in Lass 2 KO liver than the WT control, indicating that the deletion of Lass 2 inhibits apoptosis in liver tissue. (D) The histogram of average EdU-positive ratio, PCNA-positive ratio and TUNEL-positive ratio. ${ }^{* * *} \mathrm{P}<0.001$, Lass $2 \mathrm{KO}$ vs. WT. DEN, diethylnitrosamine; Lass2 KO, Lass2 knockout; WT, wild-type.
A 40 weeks

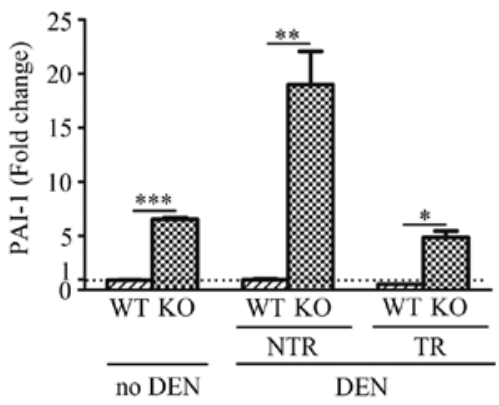

B 40 weeks

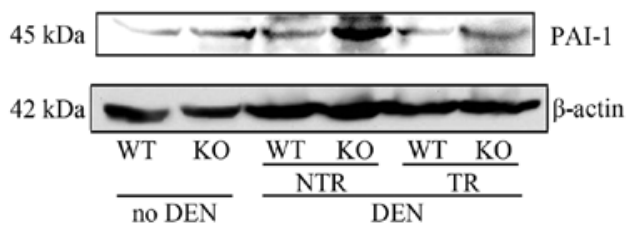

Figure 4. Increased expression of PAI-1 in Lass 2 KO livers with or without DEN-treatment. The expression of PAI-1 in Lass $2 \mathrm{KO}$ livers with or without DEN-treatment at week 40 was detected using QT-PCR analysis and western blotting. (A) The histogram shows that PAI-1 mRNA in the Lass $2 \mathrm{KO}$ livers with or without DEN-treatment was markedly increased when compared with each individual WT counterpart. (B) Western blotting indicates an increased level of PAI-1 protein coincident with the result of the QT-PCR analysis. ${ }^{*} \mathrm{P}<0.05,{ }^{* * *} \mathrm{P}<0.001$, Lass 2 vs. WT. PAI-1, plasminogen activator inhibitor type-1; Lass2 KO, Lass2 knockout; DEN, diethylnitrosamine; WT, wild-type.

increase in the EdU-positive ratio $(\mathrm{P}<0.001)$ and an $\sim 12$-fold increase in the PCNA-positive ratio $(\mathrm{P}<0.001)$ in Lass $2 \mathrm{KO}$ mice when compared with the control. Moreover, TUNEL staining demonstrated that the average TUNEL-positive ratio was dramatically decreased in the liver tissues of Lass $2 \mathrm{KO}$ mice when compared with the control $(\mathrm{P}<0.001)$ (Fig. 3D). The results suggest that the deletion of Lass2 promoted the proliferation and decreased the apoptosis of the liver tissues.

Hepatocyte-specific deletion of Lass 2 upregulates the expression of PAI-1 in liver tissues. PAI-1 is a tumour-promoting gene predominantly produced by hepatocytes in liver tissue. We used QT-PCR, western blotting and IHC to compare the expression of PAI-1 in the liver tissues of the Lass $2 \mathrm{KO}$ and control mice at week 40 with or without treatment of DEN, including respective tumour regions (TR) and non-tumour regions (NTR). The results indicated, in each paired liver tissues from Lass $2 \mathrm{KO}$ and WT mice, markedly increased mRNA and protein levels of PAI-1 in the Lass $2 \mathrm{KO}$ mice when compared with the WT counterparts. Without DEN treatment, mRNA levels of $P A I-1$ increased $\sim$-fold. After DEN-treatment, before transformation (i.e. in NTR), the mRNA level of PAI-1 in the Lass2 KO liver increased even more than that in the WT counterpart, with an increase of 20 -fold; whereas after transformation, i.e., in the TR, this increase was decreased $\sim 9$-fold (Fig. 4A). The alteration of the protein level of PAI-1 was in accordance with that of the mRNA level (Fig. 4B).

Alterations in PAI-1-associated genes TGF- $\beta 1$ and Smad-4 and -7 in Lass2 KO liver tissues. We used QT-PCR to detect 
A 40 weeks

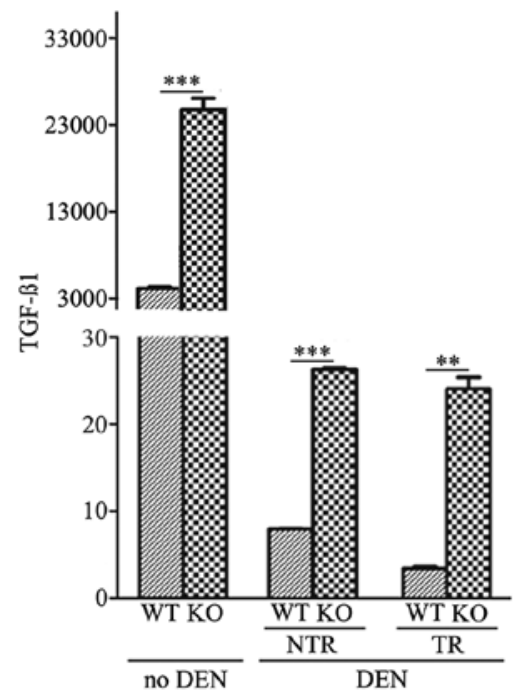

B 40 weeks

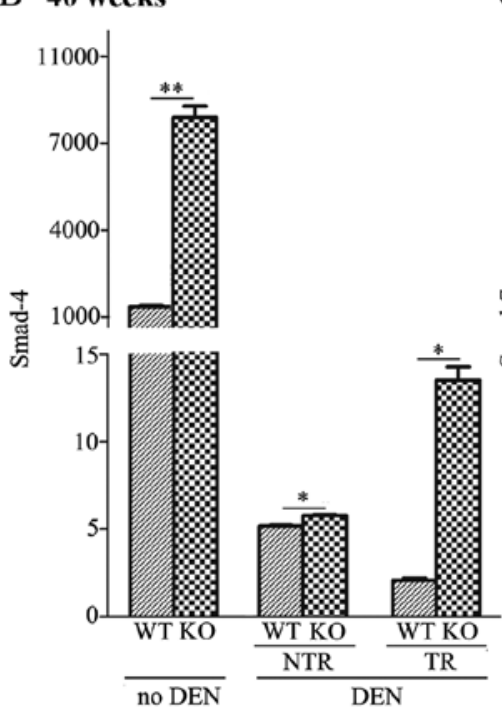

C 40 weeks

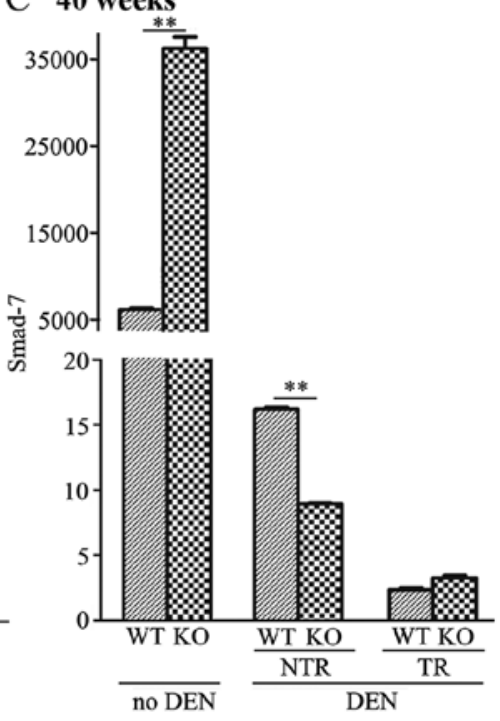

D

40 weeks
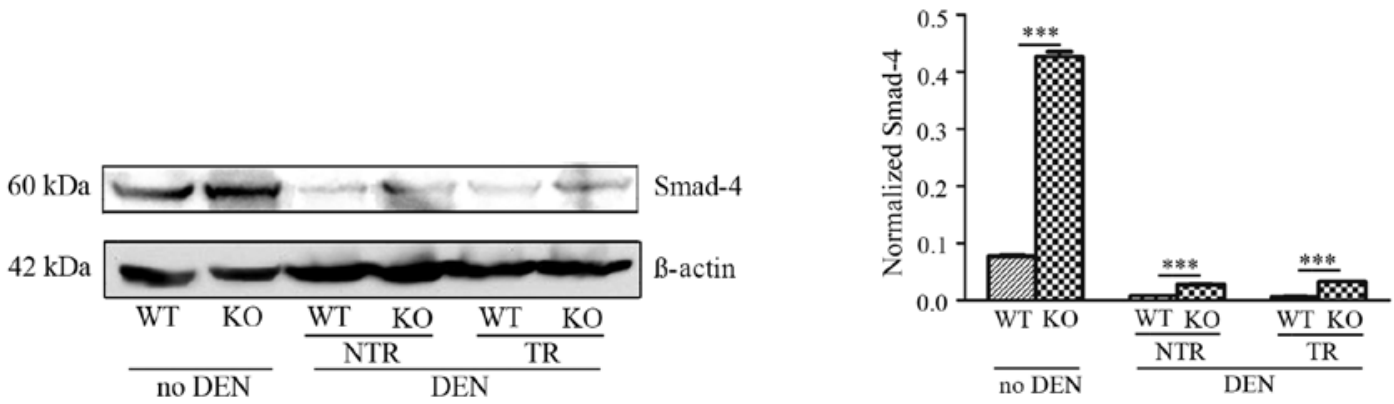

Figure 5. Increased expression of TGF- $\beta 1$ and Smad-4 in Lass2 KO livers. The expression levels of (A) TGF- $\beta 1$, (B) Smad-4 and (C) Smad-7 in Lass2 KO livers with or without DEN-treatment at week 40 were respectively detected using QT-PCR analysis. (D) Smad-4 expression was also assessed by western blot analysis. The results demonstrated that without DEN treatment, the deletion of Lass 2 caused an increase in TGF- $\beta 1\left(\sim 7\right.$-fold, $\left.{ }^{* * *} \mathrm{P}<0.001\right)$, Smad-4 $(\sim 4$-fold, $\left.{ }^{* *} \mathrm{P}<0.01\right)$ and Smad-7 $\left(\sim 6\right.$-fold, $\left.{ }^{* *} \mathrm{P}<0.01\right)$, which was parallel to the evaluated level of PAI-1. Following DEN treatment, for each Lass $2 \mathrm{KO}$ and WT paired specimen, mRNA levels of TGF- $\beta 1$, mRNA and protein levels of Smad-4 in Lass 2 KO specimen (including NTR and TR) respectively increased when compared with the WT; whereas for the mRNA level of Smad-7, a significant decrease in Lass 2 KO NTR was observed and no significant difference in Lass 2 KO TR was noted, which exhibited a different pattern of alteration to TGF- $\beta 1$ or Smad-4. Lass $2 \mathrm{KO}$, Lass 2 knockout; DEN, diethylnitrosamine; NTR, non-tumour regions; TR, tumour regions; WT, wild-type.

the mRNA levels of TGF- $\beta 1$ and Smad-4 and -7, genes reported to be closely related with PAI-1, in Lass $2 \mathrm{KO}$ and WT liver tissues. Smad-4 expression was also assessed by western blot analysis. The results demonstrated that without DEN treatment, the deletion of Lass 2 caused increases in TGF- $\beta 1$, Smad-4 and -7, which were parallel to the levels of $P A I-1$. Following DEN treatment, in each Lass $2 \mathrm{KO}$ and WT paired specimen, mRNA levels of TGF- $\beta 1$ and Smad-4 in the Lass $2 \mathrm{KO}$ specimen (including NTR and TR), respectively, were increased when compared to the WT; whereas regarding the mRNA level of Smad-7, a significant decrease was noted in Lass2 KO NTR, and no significant difference was noted in Lass $2 \mathrm{KO}$ TR, which exhibited a different pattern of alteration to TGF- $\beta 1$ and Smad-4 (Fig. 5A-C). Western blotting of Smad-4 showed a similar trend with the result of QT-PCR analysis (Fig. 5D). Taken together, in each pair of Lass2 KO and WT specimens, the TGF- $\beta 1$, Smad-4 and PAI- 1 from the Lass $2 \mathrm{KO}$ group was consistently and respectively significantly increased when compared to the WT group, suggesting that upregulation of the TGF- $\beta 1$-Smad4-PAI- 1 occurred in the Lass $2 \mathrm{KO}$ mice. It was noted that mRNA levels of $T G F-\beta 1$, Smad-4 and -7, after DEN induction when compared with these levels before DEN treatment, decreased in several orders of magnitude, the significance of which is yet to be known.

\section{Discussion}

Lass 2 is a novel gene isolated from a human liver cDNA library by our laboratory and is a human homologue of the yeast longevity assurance gene Saccharomyces cerevisiae longevity assurance gene (LAG1). The deletion of Lass 2 in mice caused hepatocarcinomas after they became adults (5). Our previous study found that overexpression of Lass 2 inhibited the cell growth of the human hepatocellular carcinoma (HCC) cell line SMMC-7721 (6). Recently, Lass 2 has attracted the interest of many researchers as more and more evidence suggests that Lass2 may be a tumour-suppressor gene. Previously reported experimental data revealed that Lass 2 inhibited the growth 
of HCC $(5,6)$, suppressed invasion of a prostate cancer cell line (7) and elevated drug-sensitivity in breast cancer (8). Clinical investigation showed that the deletion of Lass 2 is positively associated with clinical stage of progression, depth of tumour invasion and recurrence of bladder carcinoma implying that Lass 2 may be a prognostic indicator for this type of carcinoma (9). Comprehensive laboratory and clinical data strongly support that Lass2 is an effective tumour-suppressor gene, and inhibits the proliferation and metastasis of several types of cancer.

In the present study, to the best of our knowledge, we first produced hepatocyte-specific Lass2-deficient mice. The results of the EdU assay, PCNA histochemistry and TUNEL staining demonstrated the increased proliferation and attenuated apoptosis in Lass $2 \mathrm{KO}$ liver tissue when compared with the control. We treated the Lass $2 \mathrm{KO}$ mice and WT mice with the carcinogen DEN and found that Lass $2 \mathrm{KO}$ mice developed liver tumours earlier than the control group. At week 23 following treatment of DEN, 100\% Lass $2 \mathrm{KO}$ mice developed obvious liver tumours whereas only $21.4 \%$ of mice in the control group developed tumours, for which the occurrence between the 2 genotypes was of marked difference. The deletion of Lass 2 not only promoted the occurrence of liver tumours, but also accelerated the development of liver tumours. At week 40 after treatment of DEN, in the Lass $2 \mathrm{KO}$ mice, the number of tumours on the liver were more numerous $(\mathrm{P}<0.001)$ and the average size of liver tumours were larger than in the WT mice $(\mathrm{P}<0.001)$. Our data provide obvious evidence that Lass2 is a protective gene against DEN-induced carcinogenesis.

The mechanism by which Lass 2 suppresses tumours may rely upon several factors. One mechanism is related to the ceramids that are produced by Lass 2 . Lass 2 , a ceramid synthesase, is responsible for generating a long-chain spectrum of ceramids, which act as secondary messengers and regulate cell proliferation and apoptosis $(16,17)$. Another mechanism by which Lass 2 suppresses tumours is via the interaction with the $\mathrm{c}$ subunit of vacuolar ATPase (V-ATPase) $(7,8)$. V-ATPase, a proton pump, plays an important role in carcinogenesis by regulation of intracellular and extracellular $\mathrm{pH}$, promoting carcinogenesis $(18,19)$. Lass 2 interferes with the proton secretion of tumour cells to produce an unfavorable environment for the malignancy of tumour cells. The present study elucidated another novel pathway associated with the promotion of development of hepatocellular cancer in Lass2 $\mathrm{KO}$ mice.

Our results demonstrated a significant alteration in PAI-1 mRNA and protein levels in Lass2 KO liver when compared with the control mice. According to previous reports, PAI-I plays an important role in several malignant processes, such as the promotion of tumour cell proliferation $(21,25)$, inhibition of apoptosis $(22,23)$, suppression of invasion and metastasis $(24-26)$ and enhancement of angiogenesis $(27,28)$ and in the clinic, high PAI-1 levels are associated with poor prognosis for several different types of tumours (29-32). Yet, there are also controversial reports in regards to the association between $P A I-1$ and the metastasis of tumours. For example, the transfection of PAI-1 was found to inhibit the liver metastasis of pancreatic cancer by preventing angiogenesis (33). Moreover, the PAI-1-related pathway was found to be different in primary cancers and metastases (34). In the present study, the mRNA and protein levels of PAI-1 in liver tissue from the non-DEN-treated Lass2 KO and WT mice were detected and compared, which were determined as basal levels. The basal level of PAI-1 was markedly increase in Lass $2 \mathrm{KO}$ when compared to the WT mice $(\sim 8$-fold increase; $\mathrm{P}<0.001)$. Following DEN treatment, in both the TR and NTR, the PAI-1 levels in the Lass $2 \mathrm{KO}$ livers were significantly higher than levels in the WT mouse tissues $(\mathrm{P}<0.05)$. After DEN treatment, before transformation (i.e. in NTR), the mRNA level of PAI-1 in the Lass $2 \mathrm{KO}$ liver increased even more than that of the WT counterpart, with a fold increase of $\sim 20$-fold; whereas after transformation, i.e. in the TR this fold increase was decreased $\sim 9$-fold. One of the possible explanations may be the different role that Lass2-regulated PAI-1 plays before and after transformation. Taken into consideration the treatments or regions, in each paired liver tissue from the Lass2 KO and WT mice, the mRNA and protein levels of PAI-1 in the Lass2 KO liver were markedly increased when compared to the WT mouse liver tissues.

$T G F-\beta 1$ is an effective inducer of $P A I-1$ expression and the Smad pathway mediates the induction of $P A I-1$ by TGF- $\beta(35,36)$. Therefore, we detected the level of TGF- $\beta 1$ in Lass2 KO livers and WT control. The results demonstrated that the deletion of Lass 2 caused significantly increased $T G F-\beta 1$, Smad -4 and -7 levels, which were parallel to PAI- 1 in the condition of non-DEN treatment (basal level). Following DEN treatment, the mRNA levels of TGF- $\beta 1$, Smad-4 and -7 were markedly decreased when compared to basal levels, and the significance of this is yet to be revealed. However, for each paired specimen of Lass2 KO and WT tissue, mRNA levels of TGF- $\beta 1$ and Smad-4 in the Lass 2 KO livers were significantly higher than those of the WT counterparts (both in TR and NTR, respectively), whereas no significant difference in mRNA levels of Smad-7 was observed in the TR and these levels were significantly decreased in NTR in the Lass2 KO group. The data revealed that the mRNA levels of $T G F-\beta 1$, Smad- 4 and PAI- 1 were significantly increased in the Lass $2 \mathrm{KO}$ livers when compared with the WT livers despite of the different treatments or regions, parallel to the increase in PAI-1. These results suggest that the elevated levels of PAI-I in Lass $2 \mathrm{KO}$ liver may be the result of upregulation of the TGF- $\beta 1-S m a d 4-P A I-1$ axis. This warrants further exploration for confirmation. Although previous reports indicate that the elevated level of TGF- $\beta 1-P A I-1$ is associated with metastasis (37-39), metastasis of HCC in both groups was not observed in the present study.

In summary, the present study demonstrated that Lass2 is a protective gene against DEN-induced liver carcinogenesis, and deletion of Lass2 in hepatocytes results in the earlier occurrence of DEN-induced tumours and more rapid tumour growth, coincident with elevated levels of the TGF- $\beta 1$-Smad4-PAI-1 axis, which may be a Lass2-associated pathway and the contributor of the accelerated carcinogenesis in Lass2 $\mathrm{KO}$ mice.

\section{Acknowledgements}

This work was supported by grant from the State Key Laboratory of Oncogenes and Related Genes (No. 90-10-02, to X.L.) and the Shanghai Municipal Program of International 
Cooperation in Science and Technology (No. 12410709800, to W.Q.). The authors thank the Shanghai Research Centre for Model Organisms for their support in the establishment of the Lass $2 \mathrm{KO}$ transgenic mice used in the experiment.

\section{References}

1. Pewzner-Jung Y, Ben-Dor S and Futerman AH: When do Lasses (longevity assurance genes) become CerS (ceramide synthases)? insights into the regulation of ceramide synthesis. J Biol Chem 281: 25001-25005, 2006.

2. Teufel A, Maass T, Galle PR and Malik N: The longevity assurance homologue of yeast lag1 (Lass) gene family (Review) Int J Mol Med 23: 135-140, 2009.

3. Laviad EL, Albee L, Pankova-Kholmyansky I, et al: Characterization of ceramide synthase 2: tissue distribution, substrate specificity, and inhibition by sphingosine 1-phosphate. J Biol Chem 283: 5677-5684, 2008.

4. Becker I, Wang-Eckhardt L, Yaghootfam A, Gieselmann V and Eckhardt M: Differential expression of (dihydro)ceramide synthases in mouse brain: oligodendrocyte-specific expression of CerS2/Lass2. Histochem Cell Biol 129: 233-241, 2008.

5. Imgrund S, Hartmann D, Farwanah $\mathrm{H}$, et al: Adult ceramide synthase 2 (CERS2)-deficient mice exhibit myelin sheath defects, cerebellar degeneration, and hepatocarcinomas. J Biol Chem 284: 33549-33560, 2009.

6. Tang N, Jin J, Deng Y, et al: Lass2 interacts with V-ATPase and inhibits cell growth of hepatocellular carcinoma. Sheng Li Xue Bao 62: 196-202, 2010 (In Chinese).

7. Xu X, You J and Pei F: Silencing of a novel tumor metastasis suppressor gene Lass2/TMSG1 promotes invasion of prostate cancer cell in vitro through increase of vacuolar ATPase activity J Cell Biochem 113: 2356-2363, 2012.

8. Fan S, Niu Y, Tan N, et al: Lass 2 enhances chemosensitivity of breast cancer by counteracting acidic tumor microenvironment through inhibiting activity of V-ATPase proton pump. Oncogene 32: 1682-1690, 2012.

9. Wang H, Wang J, Zuo Y, et al: Expression and prognostic significance of a new tumor metastasis suppressor gene Lass 2 in human bladder carcinoma. Med Oncol 29: 1921-1927, 2012.

10. Binder BR, Christ G, Gruber F, et al: Plasminogen activator inhibitor 1: physiological and pathophysiological roles. News Physiol Sci 17: 56-61, 2002.

11. Jing Y, Kovacs K, Kurisetty V, Jiang Z, Tsinoremas N and Merchan JR: Role of plasminogen activator inhibitor-1 in urokinase's paradoxical in vivo tumor suppressing or promoting effects. Mol Cancer Res 10: 1271-1281, 2012.

12. Bajou K, Noël A, Gerard RD, et al: Absence of host plasminogen activator inhibitor 1 prevents cancer invasion and vascularization. Nat Med 4: 923-928, 1998.

13. Gutierrez LS, Schulman A, Brito-Robinson T, Noria F, Ploplis VA and Castellino FJ: Tumor development is retarded in mice lacking the gene for urokinase-type plasminogen activator or its inhibitor, plasminogen activator inhibitor-1. Cancer Res 60 5839-5847, 2000.

14. Kocic J, Bugarski D and Santibanez JF: SMAD3 is essential for transforming growth factor- $\beta 1$-induced urokinase type plasminogen activator expression and migration in transformed keratinocytes. Eur J Cancer 48: 1550-1557, 2012.

15. Konrad L, Scheiber JA, Schwarz L, Schrader AJ and Hofmann R: TGF- $\beta 1$ and TGF- $\beta 2$ strongly enhance the secretion of plasminogen activator inhibitor- 1 and matrix metalloproteinase-9 of the human prostate cancer cell line PC-3. Regul Pept 155: 28-32, 2009.

16. Morad SA and Cabot MC: Ceramide-orchestrated signalling in cancer cells. Nat Rev Cancer 13: 51-65, 2013

17. Ponnusamy S, Meyers-Needham M, Senkal CE, et al: Sphingolipids and cancer: ceramide and sphingosine-1-phosphate in the regulation of cell death and drug resistance. Future Oncol 6: 1603-1624, 2010.

18. Fais S, De Milito A, You H and Qin W: Targeting vacuolar $\mathrm{H}^{+}$-ATPases as a new strategy against cancer. Cancer Res 67: 10627-10630, 2007.
19. Lu X, Qin W, Li J, et al: The growth and metastasis of human hepatocellular carcinoma xenografts are inhibited by small interfering RNA targeting to the subunit ATP6L of proton pump. Cancer Res 65: 6843-6849, 2005.

20. Nishioka N, Matsuoka T, Yashiro M, Hirakawa K, Olden K and Roberts JD: Plasminogen activator inhibitor 1 RNAi suppresses gastric cancer metastasis in vivo. Cancer Sci 103: 228-232, 2012.

21. Choi JW, Lee JH, Park HS and Kim YS: PAI-1 expression and its regulation by promoter $4 \mathrm{G} / 5 \mathrm{G}$ polymorphism in clear cell renal cell carcinoma. J Clin Pathol 64: 893-897, 2011.

22. Fang H,Placencio VR and DeClerck YA: Protumorigenic activity of plasminogen activator inhibitor-1 through an antiapoptotic function. J Natl Cancer Inst 104: 1470-1484, 2012.

23. Chen SC, Henry DO, Reczek PR and Wong MK: Plasminogen activator inhibitor-1 inhibits prostate tumor growth through endothelial apoptosis. Mol Cancer Ther 7: 1227-1236, 2008.

24. Maillard CM, Bouquet C, Petitjean MM, et al: Reduction of brain metastases in plasminogen activator inhibitor-1-deficient mice with transgenic ocular tumors. Carcinogenesis 29: 2236-2242, 2008.

25. Klein RM, Bernstein D, Higgins SP, Higgins CE and Higgins PJ: SERPINE1 expression discriminates site-specific metastasis in human melanoma. Exp Dermatol 21: 551-554, 2012.

26. Tang $L$ and Han $X$ : The urokinase plasminogen activator system in breast cancer invasion and metastasis. Biomed Pharmacother 67: 179-182, 2013.

27. Zubac DP, Wentzel-Larsen T, Seidal T and Bostad L: Type 1 plasminogen activator inhibitor $(P A I-1)$ in clear cell renal cell carcinoma (CCRCC) and its impact on angiogenesis, progression and patient survival after radical nephrectomy. BMC Urol 10: 20, 2010.

28. Jung SY, Song HS, Park SY, Chung SH and Kim YJ: Pyruvate promotes tumor angiogenesis through HIF-1-dependent PAI-1 expression. Int J Oncol 38: 571-576, 2011.

29. Allott EH, Morine MJ, Lysaght J, et al: Elevated tumor expression of PAI-1 and SNAI2 in obese esophageal adenocarcinoma patients and impact on prognosis. Clin Transl Gastroenterol 3: $\mathrm{e} 12,2012$.

30. Zhang W, Ling D, Tan J, Zhang J and Li L: Expression of urokinase plasminogen activator and plasminogen activator inhibitor type-1 in ovarian cancer and its clinical significance. Oncol Rep 29: 637-645, 2013.

31. Foekens JA, Peters HA, Look MP, et al: The urokinase system of plasminogen activation and prognosis in 2780 breast cancer patients. Cancer Res 60: 636-643, 2000.

32. Schrohl AS, Christensen IJ, Pedersen AN, et al: Tumor tissue concentrations of the proteinase inhibitors tissue inhibitor of metalloproteinases-1 (TIMP-1) and plasminogen activator inhibitor type $1(P A I-1)$ are complementary in determining prognosis in primary breast cancer. Mol Cell Proteomics 2: 164-172, 2003.

33. Inoue $\mathrm{M}$, Sawada $\mathrm{T}$, Uchima $\mathrm{Y}$, et al: Plasminogen activator inhibitor-1 (PAI-1) gene transfection inhibits the liver metastasis of pancreatic cancer by preventing angiogenesis. Oncol Rep 14: 1445-1451, 2005.

34. Malinowsky K, Wolff C, Berg D, et al: uPA and PAI-1 related signalling pathways differ between primary breast cancers and lymph node metastases. Transl Oncol 5: 98-104, 2012.

35. Chen C, Sun MZ, Liu S, et al: Smad4 mediates malignant behaviors of human ovarian carcinoma cell through the effect on expressions of E-cadherin, plasminogen activator inhibitor-1 and VEGF. BMB Rep 43: 554-560, 2010.

36. Zhu Y, Yin WL, Ba YF, et al: Transforming growth factorpromotes the transcriptional activation of plasminogen activator inhibitor type 1 in carcinoma-associated fibroblasts. Mol Med Rep 6: 1001-1005, 2012.

37. Kutz SM, Hordines J, McKeown-Longo PJ and Higgins PJ: TGF- $\beta 1$-induced PAI-1 gene expression requires MEK activity and cell-to-substrate adhesion. J Cell Sci 114: 3905-3914, 2001.

38. Humbert L and Lebrun JJ: TGF-beta inhibits human cutaneous melanoma cell migration and invasion through regulation of the plasminogen activator system. Cell Signal 25: 490-500, 2013.

39. Wilkins-Port CE, Ye Q, Mazurkiewicz JE and Higgins PJ: TGF- $\beta 1+$ EGF-initiated invasive potential in transformed human keratinocytes is coupled to a plasmin/MMP-10/MMP-1dependent collagen remodeling axis: role for PAI-1. Cancer Res 69: 4081-4091, 2009. 